Article

\title{
Exploring the Terminal Pathway of Sex Pheromone Biosynthesis and Metabolism in the Silkworm
}

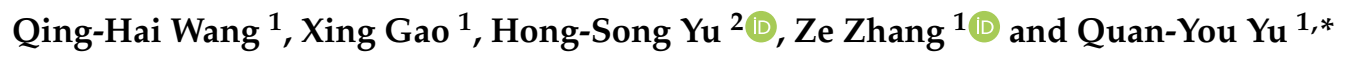 \\ 1 School of Life Sciences, Chongqing University, Chongqing 400044, China; wqh1226823@163.com (Q.-H.W.); \\ gxing202026021022@163.com (X.G.); zezhang@cqu.edu.cn (Z.Z.) \\ 2 School of Basic Medical Sciences, Zunyi Medical University, Zunyi 563000, China; yuhongsong@163.com \\ * Correspondence: yuqy@cqu.edu.cn
}

Citation: Wang, Q.-H.; Gao, X.; Yu, H.-S.; Zhang, Z.; Yu, Q.-Y. Exploring the Terminal Pathway of Sex Pheromone Biosynthesis and Metabolism in the Silkworm. Insects 2021, 12, 1062. https://doi.org/ $10.3390 /$ insects 12121062

Academic Editor:

Jean-François Picimbon

Received: 15 October 2021

Accepted: 23 November 2021

Published: 26 November 2021

Publisher's Note: MDPI stays neutral with regard to jurisdictional claims in published maps and institutional affiliations.

Copyright: (c) 2021 by the authors. Licensee MDPI, Basel, Switzerland. This article is an open access article distributed under the terms and conditions of the Creative Commons Attribution (CC BY) license (https:// creativecommons.org/licenses/by/ $4.0 /)$.
Simple Summary: Insect sex pheromone biosynthesis has received widespread attention, while the terminal pathway related to aldehyde synthesis and metabolism is still poorly understood at a molecular level. Previous studies found that the silkworm, Bombyx mori (Lepidoptera, Bombycidae), has two pheromone compounds, bombykol and bombykal, with a ratio of 11:1, while its closest wild relative, B. mandarina, only uses bombykol as a pheromone. In this study, sex pheromone gland transcriptomes were compared between the domestic and wild silkworms. All the candidate gene families were identified. Then we used the differentially expressed information, tissue and developmental expression profiles, and phylogenetic analysis to identify the putative causal genes involved in the terminal pathway. Our findings provide insights into the aldehyde synthesis and metabolism pathways and evolutionary conservation in moths.

Abstract: Sex pheromones are vital to sexual communication and reproduction in insects. Although some key enzymes in pheromone production have been well studied, information on genes involved in the terminal pathway is limited. The domestic silkworm employs a pheromone blend containing (E,Z)-10,12-hexadecadienol (bombykol) and analogous (E,Z)-10,12-hexadecadienal (bombykal); whereas, its wild ancestor B. mandarina uses only bombykol. The two closely related moths might be a good model for exploring the genes involved in aldehyde pheromone synthesis and metabolism. By deep sequencing and analyzing the sex pheromone gland (PG) transcriptomes; we identified 116 candidate genes that may be related to pheromone biosynthesis, metabolism, and chemoreception. Spatiotemporal expression profiles and differentially expressed analysis revealed that four alcohol oxidases (BmorAO1; 2; 3; and 4); one aldehyde reductase (BmorAR1); and one aldehyde oxidase (BmorAOX5) might be involved in the terminal pathway. Phylogenetic analysis showed that, except for BmorAO3 and MsexAO3, AOs did not show a conversed orthologous relationship among moths; whereas, ARs and AOXs were phylogenetically conserved. This study provides crucial candidates for further functional elucidation, and which may be utilized as potential targets to disrupt sexual communication in other moth pests.

Keywords: sex pheromone; aldehyde synthesis and metabolism; terminal pathway; silkworm

\section{Introduction}

Sex pheromones are usually biosynthesized and released from female moths using a specialized pheromone gland (PG) located at the tip of the female's abdomen [1]. Speciesspecific pheromones play a vital role in intraspecific sexual communication and interspecific reproductive isolation [2]. To date, a large number of sex pheromones have been chemically identified from more than 1600 moth species [3]. Most known pheromones (> 75\%) belong to Type-I, i.e., even-numbered $\mathrm{C}_{10}-\mathrm{C}_{18}$ acyclic and unsaturated fatty acid-derived compounds, such as alcohols, aldehydes, and acetate esters [4]. To achieve reproductive isolation, even closely related moth species will have different components, or have the 
same components but in different blend ratios $[5,6]$. Thus, species-specific pheromones are often strictly controlled by the biosynthesis and metabolism pathway [6,7].

Due to the similar molecular scaffolds of sex pheromones, biosynthetic and metabolic pathways are relatively conserved in moths [6,7]. Generally, the biosynthetic pathway of the Type-I sex pheromone is regulated by the pheromone biosynthesis-activated neuropeptide (PBAN), released from the brain-subesophageal ganglion. PBAN can migrate to PGs, where it interacts with the PBAN receptor (PBANr) in the PG cell membrane [8]. The resulting signal then triggers a series of enzymatic reactions, starting with the de novo biosynthesis of pheromone precursors, mainly $\mathrm{C}_{14}, \mathrm{C}_{16}$, or $\mathrm{C}_{18}$ saturated fatty acids, using acetyl-CoA carboxylase (ACC) and fatty acid synthase (FAS) [9]. Then, one or more double bonds are introduced into the pheromone precursors by desaturase (DES) at some specific carbon locations [10-13]. The unsaturated pheromone precursors are transformed to corresponding fatty alcohols by fatty-acyl reductase (FAR). On the one hand, the unsaturated fatty alcohols can be used as pheromone components in some moths [14-16]. They might also be converted to aldehydes or acetate esters by alcohol oxidase (AO) [17] or acetyltransferase (ACT) [18]. However, the produced aldehydes might be partially metabolized to corresponding alcohols and carboxylic acids by aldehyde reductase (AR) [19] and aldehyde oxidase (AOX) [20]. Similarly, acetate esters might be degraded into alcohols by carboxylesterase (COE) [21].

The general pathway of sex pheromone biosynthesis has been continuously improved since the first identification of bombykol in B. mori [22-24]. In the past two decades, some enzyme and non-enzyme genes involved in bombykol production have been cloned and functionally characterized in B. mori, including pgdesat1 [25,26], pgFAR [26,27], BmFATP [28], $p g A C B P$ [29], $m g A C B P$ [29], and several lipase genes [30]. Some of the homologous genes have also been identified in other moth species, such as A. pernyi [10], O. nubilalis [31,32], Yponomeuta spp. [33], S. exigua [34], and E. japonica [35]. Comparative analyses showed that the above-mentioned enzyme genes are often clustered into orthologous clades of sex pheromone synthesis in the phylogenetic trees [25,33-35], suggesting that they are highly conserved in moths.

The biosynthetic pathway of sex pheromones has received widespread attention, while the terminal pathway related to aldehyde synthesis and metabolism are still poorly understood at a molecular level. Enzyme activities of alcohol oxidase were found in the female PGs of Manduca sexta [36], Hyphantria cunea [37], Heliothis virescens, and Heliothis $z e a$ [38], which suggested that alcohol oxidase is responsible for metabolizing fatty alcohols into aldehydes. In recent years, the AO family has been identified incidentally in some moth PG transcriptomes [39-41]. Aldehyde reductase and aldehyde oxidase can metabolize fatty aldehydes and might also be involved in the terminal pathway. This speculation stems from the fact that ARs and AOXs were both distributed in PGs and antennae, and the antennal enzymes have degrading activity for aldehyde pheromones [42-44]. Earlier biochemistry studies found that antennal aldehyde oxidase from M. sexta [45], Antheraea polyphemus [20], and B. mori [20] can degrade bombykal. Recently, an AOX gene, AtraAOX2, has been cloned from the antennae of Amyelois transitella, which can degrade the main pheromone component, Z11,Z13-16:Ald [43].

The silkworm, Bombyx mori (Lepidoptera, Bombycidae), is an important beneficial insect, domesticated from the Chinese wild silkworm B. mandarina about 5000 years ago [46]. A previous study found that bombykol is the only pheromone component in $B$. mandarina [47], whereas the sex pheromone of the domestic silkworm has been determined to be a mixture of two compounds, bombykol and bombykal, with a ratio of 11:1 [47,48]. In this study, comparative transcriptomes of pheromone glands were conducted between the domestic and wild silkworms. The putative genes involved in pheromone biosynthesis and metabolism have been identified. Combining the differential expression analysis, spatiotemporal transcription profiles, and comparative genomics, the crucial candidate genes were revealed. Actually, bombykol and bombykal are used as sex pheromones by 11 and 25 species of moths, respectively (http:/ / www.pherobase.com/ (accessed on 10 
June 2021)). Our results would provide an important basis for understanding the role of terminal enzymes in regulating pheromone components and their ratios in moth pests.

\section{Materials and Methods}

\subsection{Insect Rearing}

The domestic silkworm (p50T strain) and wild silkworm (Chongqing, China) were used for the experiment in this study. Larvae of the domestic silkworms were reared on mulberry leaves in the laboratory conditions, $25 \pm 1{ }^{\circ} \mathrm{C}, 70 \% \pm 2 \%$ relative humidity (RH), and a photoperiod of $14 \mathrm{~h}$ light and $10 \mathrm{~h}$ dark. The larvae of the wild silkworms were reared on mulberry trees in the Plant Garden of Chongqing University under natural conditions until pupation. The pupae of B. mori and B. mandarina were separated by male and female, and placed in different boxes till eclosion.

\subsection{Sample Collection}

The pheromone glands were quickly excised from the 1-day-old virgin females after $3 \mathrm{~h}$ of photosensitization. PGs from 20 individuals were used for one sample. PG_D and PG_W represent the PGs of the domestic and wild silkworms, respectively. All the samples were kept in RNAlater (Qiagen, Hilden, Germany) and stored at $-80{ }^{\circ} \mathrm{C}$ till RNA extraction.

For the expression pattern analysis, various tissues were collected in the domestic silkworms, including the antennae, heads, thoraxes, abdomens (without pheromone glands), wings, and legs of the adult females. In addition, PGs from different developmental stages were also collected, including the pupal PGs (from the 4th day to the 9th day), the virgin adult PGs (3-h, 24-h, and 48-h females after eclosion), and the 3-h, 6-h, and 9-h mated adult PGs.

\section{3. cDNA Library Preparation and Illumina Sequencing}

Total RNAs from PG_D and PG_W were extracted using the TransZol Up Plus RNA Kit (TransGene, Beijing, China), following the manufacturer's instructions. A NanoDrop ND2000 spectrophotometer (Thermo Fisher Scientific, Waltham, MA, USA) was used to check RNA purity and concentration according to the absorbance at $260 \mathrm{~nm}$, and $1.0 \%$ agarose gel was used to monitor RNA degradation. The two sequencing libraries (PG_D and PG_W) were prepared by using the Illumina Gene Expression Sample Prep Kit. Briefly, mRNA from the two samples was purified using Oligo (dT) magnetic beads from $30 \mu \mathrm{g}$ of pooled total RNA. Subsequently, the mRNA was sheared into short fragments in the presence of divalent cations in fragmentation solution at $94{ }^{\circ} \mathrm{C}$ for $5 \mathrm{~min}$. The short fragments were used as templates for the first-strand cDNA synthesis. Then, the second-strand cDNA was generated using dNTPs, RNaseH, and DNA polymerase I. Short sequences were amplified by PCR and purified with the QIAquick PCR Purification Kit (Qiagen, Shanghai, China). Ultimately, the cDNA library preparations were sequenced on a HiSeq ${ }^{\mathrm{TM}} 2000$ platform (Novogene, Tianjin, China).

\subsection{Sequence Assembly and Annotation}

To obtain the clean reads, the raw reads were filtered using NGS QC Toolkit v2.3.3 software (http:/ / www.nipgr.res.in/ngsqctoolkit.html (accessed on 3 June 2020)), and adaptor sequences and low-quality sequences were removed, including $>10 \%$ of poly- $\mathrm{N}$ or $>$ $50 \%$ of bases whose Phred quality scores were $\leq 5$. Reference genome and gene model annotation files were downloaded from SilkDB v3.0 (https:/ / silkdb.bioinfotoolkits.net/ (accessed on 10 September 2020)). The paired-end clean reads from PG_D and PG_W were aligned to the B. mori reference genome using HISAT2 [49], and then the StringTie program was used for assembly [50]. The resulting transcripts were performed by BLASTX against the non-redundant (nr) protein database in NCBI with an e-value less than 1.0E-5. Subsequently, GO (Gene Ontology) annotations were performed by the Blast2GO program (https:/ / www.blast2go.com/ (accessed on 13 October 2020)). Meanwhile, using InterProScan v5.50 software (http:/ / www.ebi.ac.uk/interpro/ (accessed on 13 October 2020)), 
the amino acid sequences from protein-coding transcripts performed homology alignments against the InterPro database (http:/ / www.ebi.ac.uk/interpro/ (accessed on 15 October 2020)) to acquire more accurate annotated results. Ultimately, GO functional distributions were obtained using WEGO software (http://wego.genomics.org.cn/ (accessed on 16 October 2020)).

\subsection{Sequence Acquisition and Phylogenetic Analysis}

To understand the evolutionary conservation of the enzyme genes in the terminal pathway, some of the species containing at least one aldehyde as a pheromone were collected (Table S1). Homologous protein sequences of AOs, ARs, and AOXs were mainly retrieved from the literature (Table S2). It is worth noting that $M$. sexta shares bombykal with the silkworms. Due to no PG transcriptome data being released, homologous searches were performed by BLAST against the gene sequences based on the whole genome annotation in M. sexta downloaded from the RefSeq database (https:/ / www.ncbi.nlm.nih.gov/refseq/ (accessed on 20 May 2021)). In the silkworm, the candidate terminal enzymes were identified by a BLAST search against the transcripts of the PG transcriptomes. All the candidate enzyme genes are checked in the PFAM database (http:/ / pfam.xfam.org/ (accessed on 25 May 2021)) to see whether they contain the corresponding domains. All the candidate genes assembled in the transcriptome have a one-to-one correspondence with SilkDB v3.0 (https:/ / silkdb.bioinfotoolkits.net/ (accessed on 25 May 2021)) and SilkBase (http://silkbase.ab.a.u-tokyo.ac.jp/ (accessed on 25 May 2021)).

The alignments of multiple sequences were performed by MAFFT program (https:/ / mafft.cbrc.jp/alignment/software/ (accessed on 2 June 2021)). The optimum phylogenetic models were calculated by ModelTest-NG v0.1.6 [51]. Maximum likelihood (ML) trees were reconstructed for AOs, ARs and AOXs using the RAxML-NG v1.0.0 program [52]. Branch supports were surveyed by bootstrapping 500 replicates, and bootstrap values $(\geq 70 \%)$ were shown at the nodes.

\subsection{Reverse Transcription-Polymerase Chain Reaction (RT-PCR) Analysis}

Single-stranded cDNA was synthesized using $2 \mu \mathrm{g}$ of total RNA from each sample using a PrimeScript ${ }^{\mathrm{TM}}$ reagent Kit with gDNA Eraser (TaKaRa, Dalian, Liaoning, China), following the instruction in the manual. Gene-specific primers were designed using Primer Premier 5.0 software (Table S3). RT-PCR programs were $98{ }^{\circ} \mathrm{C}$ for $2 \mathrm{~min}$, followed by 25-32 cycles of $98{ }^{\circ} \mathrm{C}$ for $15 \mathrm{~s}, 52-58{ }^{\circ} \mathrm{C}$ for $10 \mathrm{~s}$, and $72{ }^{\circ} \mathrm{C}$ for $1 \mathrm{~min}$. A total volume of $10 \mu \mathrm{L}$ PCR reaction system was performed containing $8.4 \mu \mathrm{L}$ of Golden Star T6 Super PCR Mix (TsingKe, Beijing, China), $0.3 \mu \mathrm{L}$ of forward primer $(10 \mathrm{mM}), 0.3 \mu \mathrm{L}$ of reverse primer $(10 \mathrm{mM})$, and $1.0 \mu \mathrm{L}$ of cDNA templates $(200 \mathrm{ng} / \mu \mathrm{L})$. Amplification products were analyzed on $1.0 \%$ agarose gels. RpL3 (ribosomal protein L3) was used as an endogenous control gene to determine the consistency of the cDNA template concentration.

\subsection{Quantitative Real-Time PCR ( $q$ RT-PCR) Analysis}

Specific primers were designed and were listed in Table S4. RpL3 was used as an internal reference gene for sample normalization. The mRNA expression levels were checked using the QuantiNova SYBR Green PCR Kit (Qiagen, Shanghai, China). The PCR amplified conditions were $95^{\circ} \mathrm{C}$ for $2 \mathrm{~min}$, followed by 40 cycles of $95^{\circ} \mathrm{C}$ for $5 \mathrm{~s}$, and $58^{\circ} \mathrm{C}$ for $10 \mathrm{~s}$. Each sample was measured in three independent biological replicates, and relative mRNA expression levels were calculated using the $2^{-\Delta \Delta \mathrm{Ct}}$ method [53].

\section{Results}

\subsection{Transcriptome Sequencing, Assembly, and Functional Annotation}

RNA-sequencing (RNA-Seq) was performed on the sex pheromone glands of B. mori (PG_D) and B. mandarina (PG_W). Approximately 47.4 and 44.9 million raw reads were generated (Table S5). After removing the adaptors and low-quality sequences, the clean reads were assembled, resulting in 19,828 unique transcripts, of which 13,800 unigenes 
showed expression signals (RPKM $\geq 1$ ) in at least one of the two samples. The expressed unigenes were searched for homology in the nr and InterPro database. Based on the BLAST and InterProScan results, Gene Ontology annotations were conducted by the Blast2GO program. Three functional categories were assigned for the expressed unigenes (Figure S1). In the cellular component category, the expressed unigenes were mostly enriched in the cell (GO: 0005623) and cell part (GO: 0044464). In the molecular function category, the most enriched GO terms were the catalytic activity (GO: 0003824) and binding (GO: 0005488). In the biological process category, the most enriched were the metabolic process (GO: 0008152) and the cellular process (GO: 0009987) (Figure S1).

\subsection{Differentially Expressed Genes (DEGs) between Bombyx mori and Bombyx mandarina}

The significant DEGs between the domestic and wild silkworms were identified with a strict false discovery rate, $(\mathrm{FDR})<0.001$, and an absolute value of log2 fold-change (PG_D/PG_W) $\geq 1$. In total, 1382 DEGs were identified in the PGs, including 838 up- and 544 down-regulated genes in the domestic silkworm (Figure S2). Blast2GO software was used for GO enrichment analysis of the differentially expressed genes. They were mainly enriched in the oxidation-reduction process, the single-organism metabolic process, in oxidoreductase activity, and in the extracellular region (Figure 1A). KEGG enrichment was conducted via KOBAS 3.0 (http:/ / kobas.cbi.pku.edu.cn/anno_iden.php (accessed on 16 October 2020)). The most enriched pathways were glyoxylate and dicarboxylate metabolism, carbon metabolism, lysosome, and peroxisome (Figure 1B). The functional annotations of the DEGs indicated that there were many differences between the PGs of the domestic and wild silkworms in metabolic-related processes. To verify the reliability of transcriptome data, we checked the expression levels of sixteen candidate genes by qRT-PCR, including seven DEGs and three non-differentially expressed genes (Figure 2). The results indicated that the expression levels detected by qRT-PCR and RNA-Sequencing were comparable (Figure 2, Table S6).

(A) The most enriched GO terms

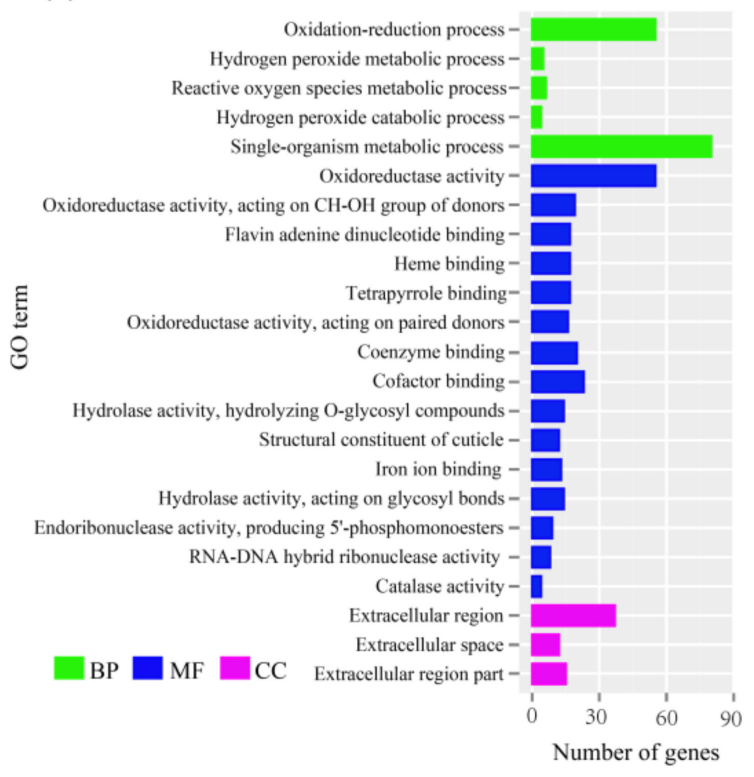

(B) The most enriched KEGG pathways

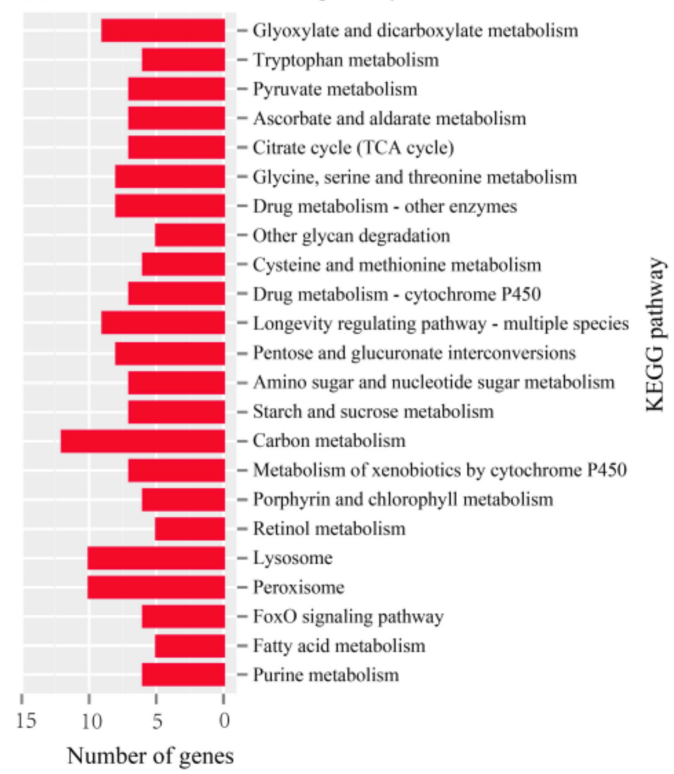

Figure 1. GO (A) and KEGG (B) enrichments of the differentially expressed genes (DEGs). GO: Gene Ontology; KEGG: Kyoto Encyclopedia of Genes and Genomes; BP: biological process; MF: molecular function; CC: cellular component. 

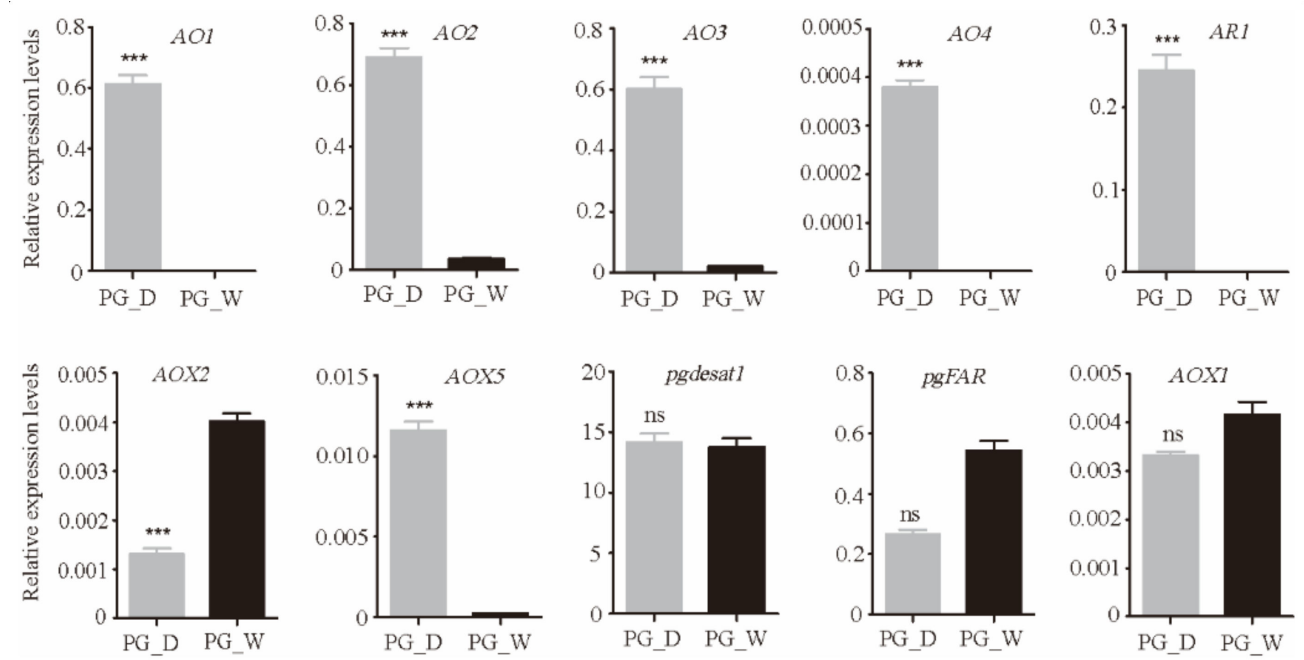

Figure 2. The qRT-PCR analysis of sixteen crucial candidate genes in the PGs (including seven DEGs and three non-DEGs). PG_D: B. mori PGs; PG_W: B. mandarina PGs; ns: no significance; ${ }^{* * *} p<0.001$, Student's t-test.

\subsection{Identification of Candidate Genes involved in Pheromone Biosynthesis and Metabolism}

Based on the homologous BLAST searches, we identified 93 putative candidate genes that encode for the following proteins: acetyl-CoA carboxylase (ACC, $n=1)$, fatty acid synthase (FAS, $n=2$ ), desaturase (DES, $n=8$ ), fatty acid transport protein (FATP, $n=6$ ), acyl-CoA-binding protein (ACBP, $n=2$ ), lipase (LIP, $n=16$ ), fatty-acyl reductase (FAR, $n=18$ ), alcohol oxidase (AO, $n=25)$, aldehyde reductase family (AR, $n=11)$, and aldehyde oxidase (AOX, $n=4$ ) (Table 1, Table S6). The results indicated that most families have multiple gene members expressed in the PGs.

Table 1. Important candidate genes related to sex pheromone biosynthesis and metabolism.

\begin{tabular}{ccccc}
\hline $\begin{array}{c}\text { Gene Name } \\
\text { (Displayed/Total) }\end{array}$ & RPKM_D & RPKM_W & DEG & Functional Annotation \\
\hline ACC1 $(1 / 1)$ & 21.40 & 21.94 & $n$ & acetyl-CoA carboxylase \\
FAS1 $(1 / 2)$ & 284.73 & 175.52 & $n$ & fatty acid synthase \\
pgdesat1 $(1 / 8)$ & 7984.24 & 7534.97 & $n$ & acyl CoA desaturase \\
BmFATP $(1 / 6)$ & 125.52 & 289.58 & $n$ & fatty acid transport protein \\
ACBP1 $(2 / 2)$ & 31.77 & 19.69 & $n$ & acyl-CoA-binding domain-containing protein \\
$A C B P 2$ & 43.40 & 53.56 & $n$ & acyl-CoA-binding domain-containing protein \\
LIP1 $(4 / 16)$ & 234.39 & 131.44 & $n$ & lipase 3 \\
LIP2 & 211.95 & 243.04 & $n$ & lipase 3-like \\
LIP3 & 81.45 & 94.26 & $n$ & lipase member H-A \\
LIP4 & 44.16 & 6.02 & lipase member H \\
pgFAR(2/18) & 215.88 & 734.50 & $n$ & fatty-acyl reductase \\
FAR2 & 255.69 & 248.61 & $n$ & putative fatty acyl-CoA reductase \\
$A O 1(3 / 25)$ & 891.26 & 2.23 & y & 15-hydroxyprostaglandin dehydrogenase \\
$A O 2$ & 925.77 & 93.66 & y & 15-hydroxyprostaglandin dehydrogenase \\
$A O 3$ & 1036.26 & 124.93 & y & carbonyl reductase [NADPH] 3 \\
$A R 1(2 / 11)$ & 582.61 & 66.52 & y & aldo-keto reductase AKR2E4-like \\
$A R 2$ & 337.63 & 718.81 & $n$ & aldo-keto reductase AKR2E4-like \\
$A O X 1(3 / 4)$ & 357.31 & 318.79 & $n$ & aldehyde oxidase 1 \\
$A O X 2$ & 48.97 & 7.67 & y & xanthine dehydrogenase-like \\
$A O X 5$ & 33.06 & 5.21 & y & xanthine dehydrogenase/oxidase
\end{tabular}

RPKM: Reads per kilobase per million mapped reads; RPKM_D: expression level in the domestic silkworm; RPKM_W: expression level in the wild silkworm. " $y$ " and " $n$ " mean differentially expressed gene (DEG) and non-differentially expressed gene. Functional annotation was obtained with a BLAST search against the nr database in NCBI. 
Since bombykol was first identified in B. mori in 1959 [14], the general pathway of sex pheromone biosynthesis has been established [22-24]. Several key genes have been cloned and functionally characterized in the silkworm, including pgdesat $1[25,26]$, $p g F A R$ [26,27], BmFATP [28], $p g A C B P$ [29], $m g A C B P$ [29], and four lipase genes [30]. These reported key genes showed abundant expression levels in the PGs (Table 1, Table S6). In particular, pgdesat1 and $p g F A R$ are the two most studied genes [25-27]. Compared with other desaturases $(R P K M<30)$ and FARs (most RPKM $<20)$, their expression levels reached 7984.24 and 215.88, respectively (Table 1, Table S6). Tissue expression profiles indicated that $p g d e s a t 1$ and $p g F A R$ were specifically expressed in PGs (Figure 3) and began to be expressed in day 7 pupae (Figure 4). Several studies showed that sexual mating can not only down-regulate gene expression but also result in the termination of sex pheromone production [54-56]. We found that pgdesat 1 and $p g F A R$ displayed significantly down-regulated expression after mating (Figure 5). In general, the causal genes involved in the pheromone biosynthesis often have characteristic expression profiles, which may provide an important reference for the identification of the genes involved in the terminal steps of the biosynthetic and metabolic pathways.
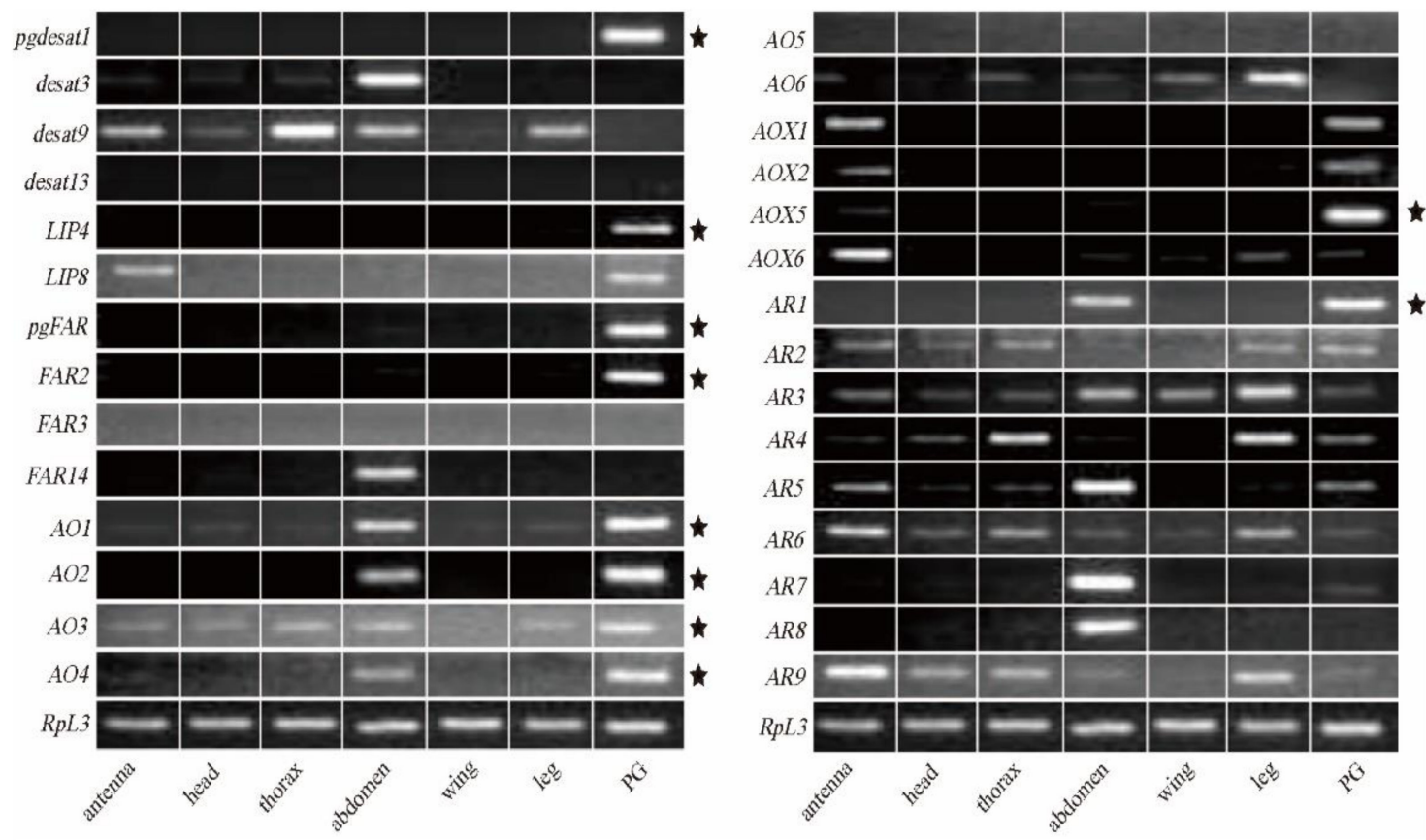

Figure 3. Expression patterns of sex pheromone biosynthesis-related genes in adult tissues. The RT-PCR products were detected by agarose gel electrophoresis. RpL3 was used as an internal reference gene. Genes with an asterisk indicate a specific or biased expression in the PGs.

\subsection{Genes involved in the Terminal Pathway of Bombykal Synthesis and Metabolism}

It was suggested that AOs, ARs, and AOXs might play roles in aldehyde pheromone synthesis and metabolism $[19,20,38]$. In this study, we comprehensively characterized the putative causal genes in the terminal pathway and revealed the phylogenetic relationships with other moths. 

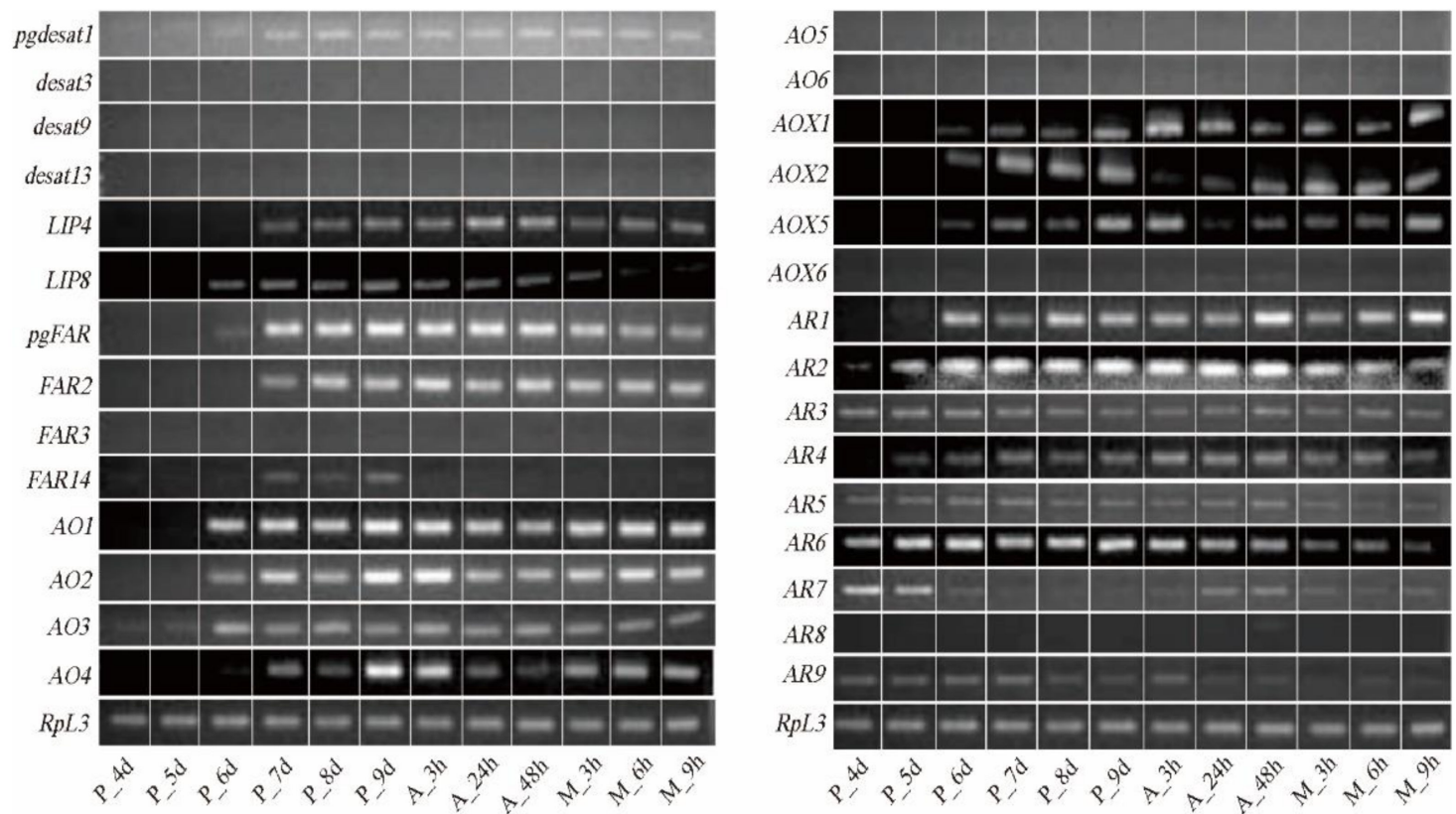

Figure 4. Expression patterns of sex pheromone biosynthesis- and metabolism-related genes in the PGs at different developmental stages. The RT-PCR products were detected by agarose gel electrophoresis. PG scheme P_4d to P_9d: the PGs from the 4th to 9th day of the pupae; A_3h, A_24h and A_48h: the virgin PGs from the 3-h, 24-h and 48-h old adults; M_3h, M_6h and M_9h: the 3-h, 6-h, and 9-h mated adult PGs.
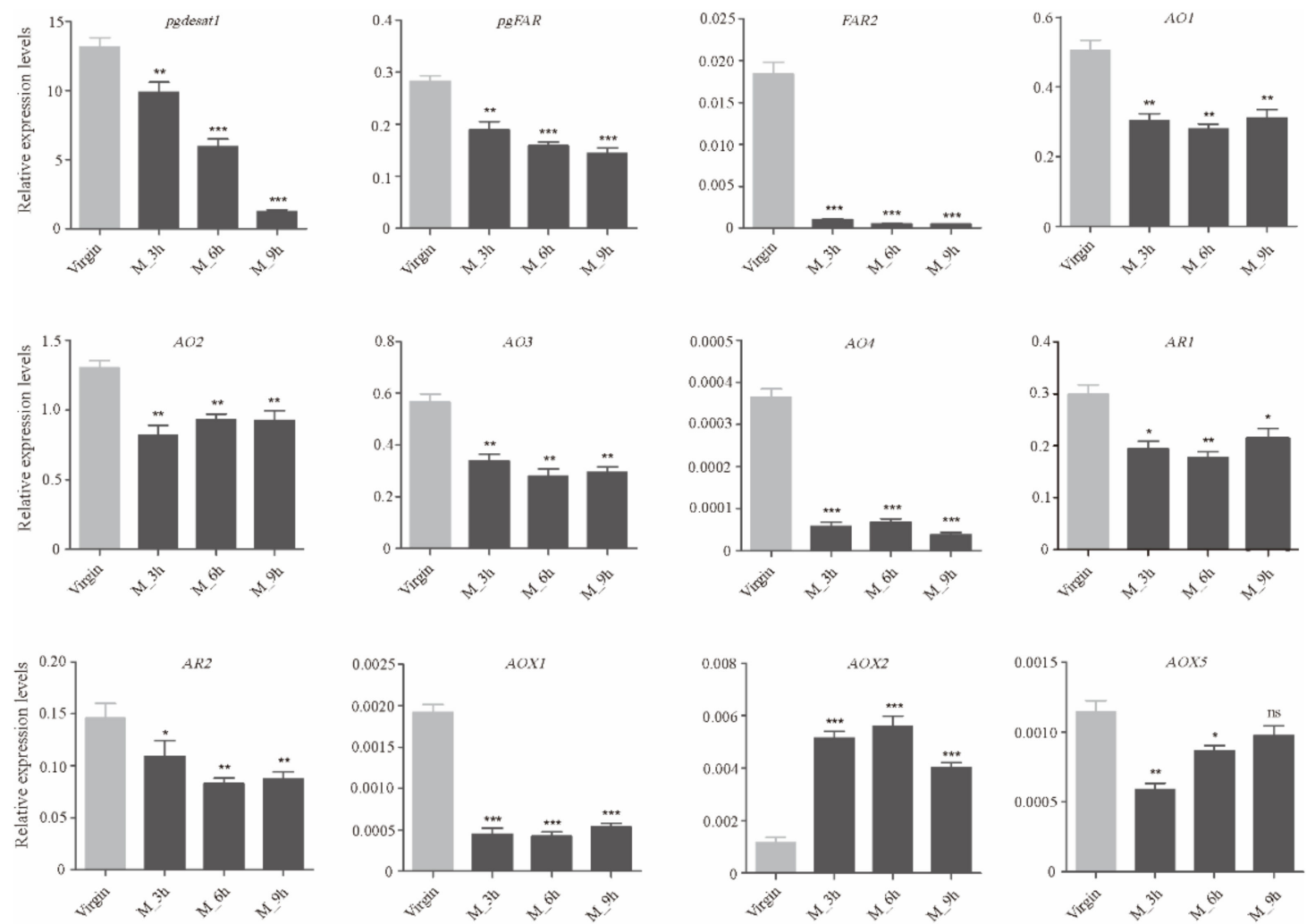

Figure 5. Effects of mating on expression of important candidate genes. The asterisk indicates significant difference between the virgin and mated PGs (ns: no significance; $p<0.05$, "**”; $p<0.01$, “**”; $p<0.001$, “***”, Student's t-test). 


\subsubsection{Alcohol Oxidase (AO)}

Early studies have shown that alcohol oxidase is responsible for the conversion of fatty alcohol into analogous aldehyde pheromones [57]. In the present study, we identified 25 AOs in the PG transcriptomes, of which six genes showed differential expression between the domestic and wild silkworms (Table S6). For the six DEGs, five of them were up-regulated in the domestic silkworm, and BmorAO1, 2, and 3 were highly expressed (Table S6). Expression profiles of all the six differentially expressed $\mathrm{AO}$ genes were detected in the various tissues of the female adults (Figure 3). BmorAO1, 2, and 4 were specifically expressed in PGs and abdomens (without pheromone glands). BmorAO3 showed high expression in PGs and was expressed at low levels in the other five tissues. However, the differentially expressed BmorAO5 and 6 were not detected expression signals in the domestic silkworm PGs (Figure 3). We also found that BmorAO1, 2, 3, and 4 began to be expressed in the PGs in day 6 or 7 pupae (Figure 4), and were down-regulated after sexual mating (Figure 5). Taken together, BmorAO1, 2, 3, and 4 might be the putative causal genes in the process of $B$. mori catalyzing bombykol to bombykal.

To understand the evolutionary relationship of $\mathrm{AO}$ genes among moths, a maximum likelihood (ML) phylogenetic tree was constructed (Figure S3). Most of the AO protein sequences were retrieved from the published PG transcriptome data [39-41,58]. Manduca sexta shares bombykal with the silkworm, and its whole genome was released. The genome-wide identification of the $\mathrm{AO}$ gene family was also conducted in M. sexta. The ML tree indicated that most of the putative causal genes (BmorAO1, 2, 3, and 4) had no clear orthologous genes. Only BmorAO3 and MsexAO3 were orthologous genes, and their sequence identity was $72.6 \%$. This result indicates that pheromone biosynthesis AOs may not be as conserved in moths as the key genes have been reported.

\subsubsection{Aldehyde Reductase (AR)}

In the terminal pathway, aldehyde reductase is mainly responsible for changing aldehyde to alcohol, which is a reverse process of alcohol oxidase [42]. Eleven ARs were identified in the PGs (Table S6). BmorAR1 showed differential expression between the domestic and wild silkworm and was highly expressed $(\mathrm{RPKM}=582.61)$ in the PGs of B. mori (Table S6). Meanwhile, BmorAR1 displayed a PG-biased expression (Figure 3) and began to express in the PGs in day 6 of pupae (Figure 4). Furthermore, its transcriptional level was significantly decreased in the mated PGs compared with the virgin PGs (Figure 5). All the experimental datasets suggested that BmorAR1 might be the key gene responsible for the reduction of bombykal in the pheromone gland. Interestingly, the phylogenetic analysis found that BmorAR1, MsexAR1, HassAR3, and AperAR5 clustered in a separated clade (Figure 6). Their protein sequence identities reached $53-57 \%$. Thus, aldehyde reductase involved in the terminal pathway might be relatively conserved in moths.

\subsubsection{Aldehyde Oxidase (AOX)}

Aldehyde oxidases (AOXs) are molybdo-flavoenzymes that oxidize aliphatic/aromatic aldehydes into the corresponding carboxylic acids [44,59]. In insects, many studies have focused on the odorant degradation of AOXs in the antennal tissue, including pheromone and aldehyde signaling molecules from host plants [43-45]. It is speculated that AOXs in the pheromone gland may participate in the degradation of aldehyde pheromone and regulate its content [60]. In the silkworm, eight AOX genes have been identified in the whole genome [61,62]. In our PG transcriptome datasets, four AOXs showed expression signals, namely BmorAOX1, 2, 5, and 6 (Table S6). BmorAOX2 and BmorAOX5 showed differential expression, and both of them were up-regulated in the domestic silkworm (Figure 2, Table S6). Tissue expression pattern analysis indicated that BmorAOX5 was specifically expressed in B. mori PGs, and BmorAOX1 and BmorAOX2 were specifically expressed in the antennae and PGs (Figure 3). Meanwhile, BmorAOX1, 2, and 5 began to express in PGs at day 6 of pupae development (Figure 4), and BmorAOX1 and BmorAOX5 were down-regulated after mating (Figure 5). A previous study found that BmorAOX5 
can metabolize multiple aromatic aldehydes and fatty aldehydes in vitro [60]. Combining the spatiotemporal expression patterns and down-regulation after mating, we suggested that the differentially expressed BmorAOX5 might be the putative causal gene mediating content of bombykal in the PGs of the domestic silkworm.

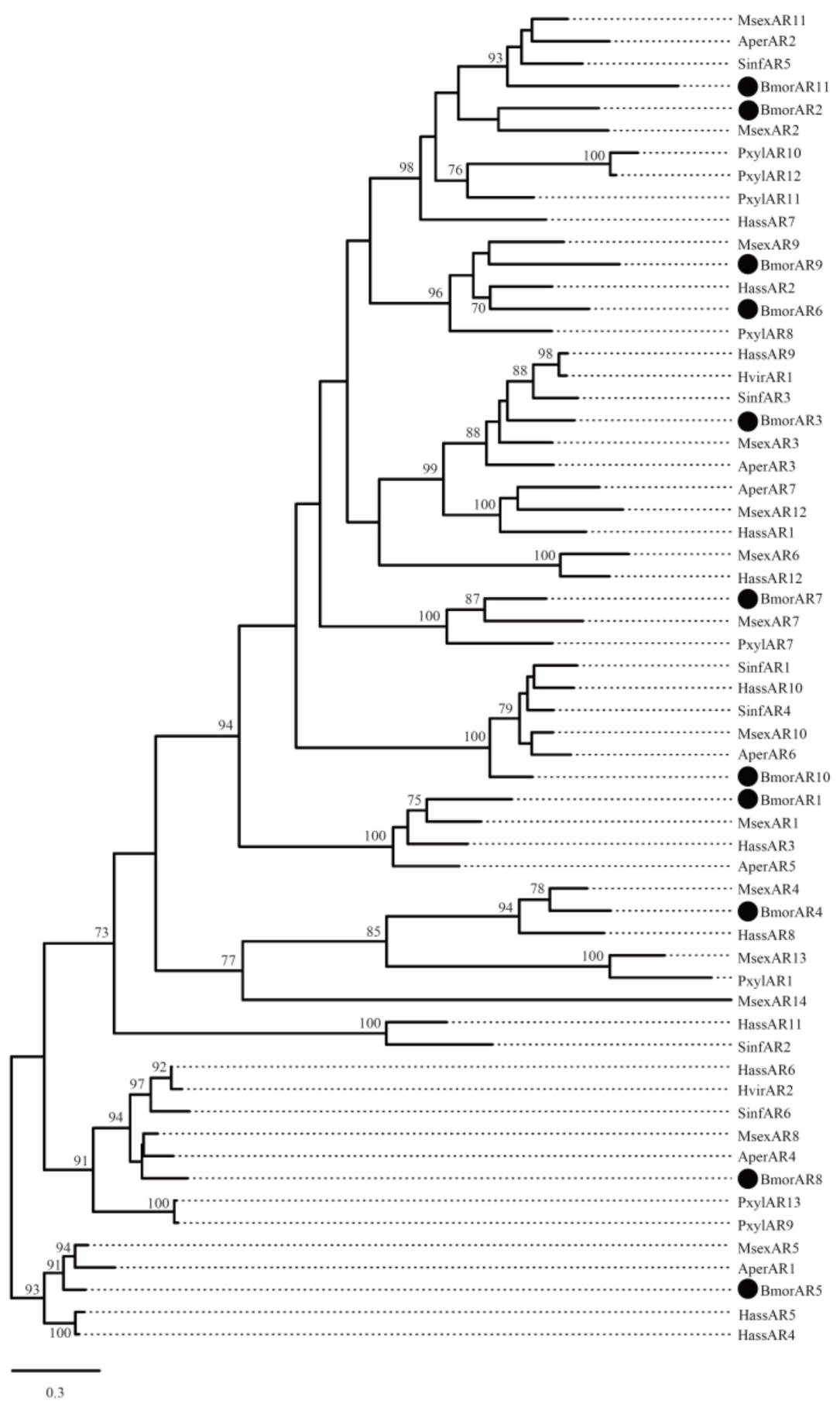

Figure 6. Phylogenetic tree of insect aldehyde reductases (ARs). Other moth AR proteins were given in Table S2. The B. mori genes are marked with a black circle. Bootstrap values $\geq 70 \%$ are shown.

Similarly, the phylogenetic tree of AOXs was also constructed (Figure 7). It was indicated that the four silkworm AOXs and other moth AOXs were clustered into four different clades, namely, AOX1, AOX2, AOX5, and AOX6. For instance, in the AOX5 clade, BmorAOX5, MsexAOX5, and SinfAOX3 showed a 1:1:1 orthologous relationship. It was suggested that the AOX family is relatively conserved during evolution. This may provide 
an important basis for revealing the universal mechanism of moth insects regulating the content of aldehyde pheromones.

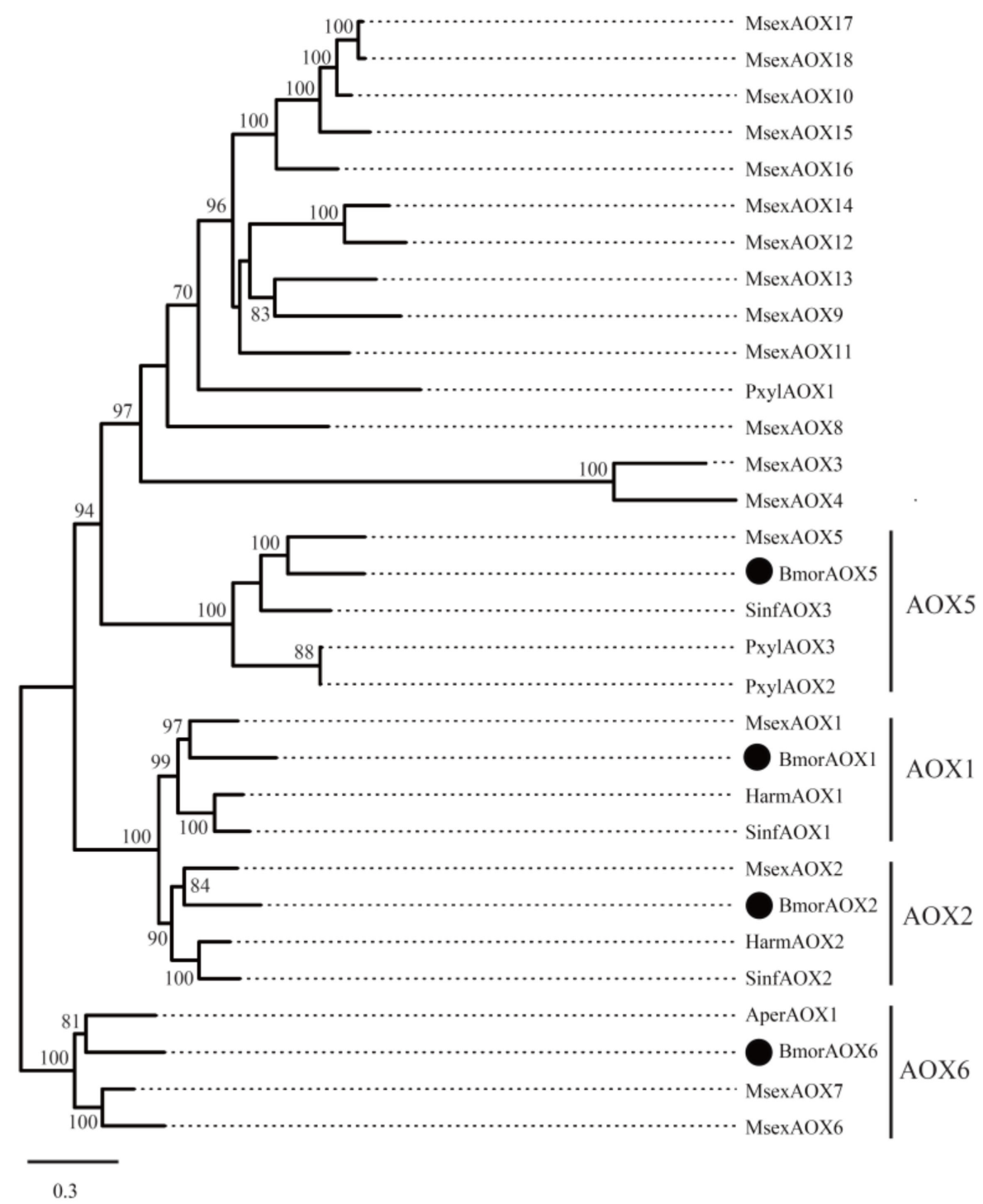

Figure 7. Phylogenetic tree of insect aldehyde oxidases (AOXs). Other moth AOX proteins were given in Table S2. The B. mori genes are marked with a black circle. Bootstrap values $\geq 70 \%$ are shown.

\section{Discussion}

In moth species, the general pathway of sex pheromone biosynthesis has been established since the first identification of bombykol in 1959 [14]. In this study, earlier verified genes were characterized again in the silkworm, such as pgdesat1, $p g F A R, B m F A T P$, etc. They often presented specific and high expression in the PGs (Figure 3, Table S6). Those key genes showed no differential expression between the domestic and wild silkworms (Table S6). This may be because they are involved in the synthesis of pheromone precursors and bombykol, and in these components, there is no difference between B.mori and B. mandarina. In addition, two FAR genes exhibited different preferences for $C_{14}$ and $C_{16}$ fatty acid substrates in Spodoptera exigua [34]. In the silkworm, pgFAR is responsible for catalyzing the biosynthesis of bombykol [27]. Based on our experiments, another PG-specific FAR2 has great consistency with $p g F A R$, such as abundant expression in adult PGs (RPKM $=255.69)$, initiation of expression in late pupal PGs, and down-regulation after mating (Figure 3, Figure 4, Figure 5, Table S6). Except for $p g F A R$, whether the silkworm also has a second functional FAR involved in the synthesis of bombykol deserves further study. 
B. mori females produce two sex pheromone components in their PGs, the major bombykol and the minor bombykal pheromones with a ratio of $11: 1$, whereas $B$. mandarina females utilize only bombykol as a pheromone $[47,48]$. In this study, we found that those genes related to bombykol synthesis and the early steps in the pathway have no expression differences between the domestic and wild silkworms (Table S6). We suspected that the difference in the pheromone component may be caused by the terminal pathway. Previous studies indicated that alcohol oxidase is involved in the conversion of fatty alcohol into analogous aldehyde pheromone [37,57]. It has also been found that alcohol oxidase can catalyze the production of $(9 Z, 12 Z, 15 Z)-9,12,15$-octadecatrienal from ${ }^{13} \mathrm{C}$-labeled linolenyl alcohol, and can also catalyze other $\mathrm{C}_{18}$ and $\mathrm{C}_{19}$ fatty alcohols to produce corresponding aldehydes in the pheromone gland of Hyphantria cunea [37]. In this study, four differentially expressed alcohol oxidase genes (BmorAO1, 2, 3, and 4) were suggested as bombykol-tobombykal conversion enzymes (Figure 3, Figure 4, Figure 5), which were involved in the terminal pathway. Since fatty-acyl desaturase and fatty-acyl reductase are highly conserved in the moth species $[25,33,34]$, we are interested in the evolutionary conservation of enzyme genes involved in the terminal steps. Based on the phylogenetic analysis of AO genes in moths containing aldehyde pheromone (Figure S3), it was shown that the putative causal $\mathrm{AO}$ genes had no orthologous genes with other species, except for BmorAO3 and MsexAO3. Is it because both $B$. mori and $M$. sexta contain bombykal? Whether the conserved $A O 3$ orthologous gene is involved in the bombykal synthesis of the two species is worthy of further functional verification.

Previous studies suggested that aldehyde pheromones might be metabolized to corresponding alcohols and carboxylic acids by aldehyde reductase and aldehyde oxidase, respectively $[42,44,59]$. In this study, BmorAR1 and BmorAOX5 were identified as the putative bombykal-metabolizing enzyme genes in the silkworm PGs (Figures 3-5). It is worth noting that one AR gene (AKR2E5), corresponding to BmorAR4 in this study, was cloned from the fat body on day 3 fifth-instar larvae, which can reduce carbonyl compounds in vitro, such as bombykal and 11-hexadecenal [42]. However, it was expressed only at low levels in the PGs of B. mori $(\mathrm{RPKM}=4.52)$ and B. mandarina $(\mathrm{RPKM}=10.41)$ and showed abundant expression levels in the thoraxes and legs (Figure 3), suggesting that BmorAR4 (AKR2E5) may function in other tissues instead of bombykal reductase in the PGs. In addition, aldehyde pheromones are biosynthesized and released in many moths, such as B. mori, A. pernyi, H. virescens, H. armigera, H. assulta, P. xylostell and S. inferens (Table S1). Phylogenetic trees were reconstructed for the AR and AOX genes in these species (Figures 6 and 7). BmorAR1 and its orthologous AR genes were grouped into a clade (Figure 6), and BmorAOX5, MsexAOX5, SinfAOX3, PxylAOX3, and PxylAOX2 formed a monophyletic clade (Figure 7). Thus, aldehyde-metabolic AR and AOX genes may be relatively conserved in moths.

Taken together, four AOs, BmorAR1, and BmorAOX5 were identified as the candidate enzyme genes involved in the synthesis and metabolism of bombykal in B. mori. Based on the present results, we are still not sure which one or more AOs play the role of converting bombykol to bombykal. At the same time, we do not know whether BmorAR1 and BmorAOX5 play a key role in the difference in bombykal composition between the domestic and wild silkworms. These questions need to be verified by genomic data, subsequent heterologous expression, enzyme activity analysis, and other experiments, keeping in mind the choice of cloning and heterologous protein expression. Generally, the process of sex pheromone synthesis and metabolism is actually a special aspect of fatty acid synthesis and metabolism. Fatty acid synthesis and metabolism are the basic life processes in organisms such as bacteria and insects. It is not excluded that some of the genes in sex pheromone synthesis pathway in insects are evolutionarily conserved with the homologs in bacteria, and therefore represent a possible result of common evolution between the moth sex pheromone gland and bacterial symbionts that would eventually be capable of pheromone biosynthesis. 


\section{Conclusions}

Comparative PG transcriptomes were conducted in the domestic and wild silkworms. The candidate genes involved in pheromone biosynthesis and metabolism were identified. Based on the tissue and developmental expression profile analyses, BmorAO1, BmorAO2, BmorAO3, BmorAO4, BmorAR1, and BmorAOX5 were characterized as the putative causal genes involved in the terminal pathway of bombykal synthesis and metabolism in the silkworm. Phylogenetic analysis indicated that AOs showed higher divergence among moths, and ARs and AOXs were relatively conserved during evolution. This study revealed valuable information about the terminal pathway of pheromone synthesis and metabolism, and provided important candidates for functional verification.

Supplementary Materials: The following are available online at https: / www.mdpi.com/article / 10.3390/insects12121062/s1, Figure S1: Histogram of gene ontology (GO) classification; Figure S2: The volcano plot of the differentially expressed genes (DEGs); Figure S3: Phylogenetic tree of insect alcohol oxidases (AOs). Sequences of AOs are given in Table S2. The B. mori genes are marked with a black circle. Bootstrap values $\geq 70 \%$ are shown; Table S1: Sex pheromone components in the representative moths. $n$ /a: not applicable; Table S2: Homologous proteins from other insects for phylogenetic analysis; Table S3: RT-PCR primers for the putative candidate genes; Table S4: qRT-PCR primers for the crucial candidate genes; Table S5: Summary of the clean reads mapped to the silkworm reference genome; Table S6: Identification of putative candidate genes related to pheromone biosynthesis and degradation. The accession numbers of the candidate enzyme genes in SilkDB v3.0 (https:/ / silkdb.bioinfotoolkits.net/) and SilkBase (http:/ / silkbase.ab.a.u-tokyo.ac.jp/) were listed.

Author Contributions: Conceptualization, Q.-Y.Y.; methodology, Q.-H.W. and Q.-Y.Y.; validation, Q.-H.W., X.G., and H.-S.Y.; formal analysis, Q.-H.W., H.-S.Y., and Q.-Y.Y.; investigation, Q.-H.W. and X.G.; writing-original draft preparation, Q.-H.W. and Q.-Y.Y.; writing-review and editing, Z.Z. and Q.-Y.Y.; visualization, Q.-H.W. and Q.-Y.Y.; funding acquisition, Z.Z. and Q.-Y.Y. All authors have read and agreed to the published version of the manuscript.

Funding: This study was funded by the National Natural Science Foundation of China (U20A2058), the Natural Science Foundation Project of Chongqing (cstc2020jcyj-msxmX0867), the Fundamental Research Funds for the Central Universities (2020CDJ-LHZZ-038, 2021CDJZYJH-002), and the Venture and Innovation Support Program for Chongqing Overseas Returnees (cx2018066).

Institutional Review Board Statement: Not applicable.

Data Availability Statement: The protein sequences of the identified genes were included in Table S6. All published data are available upon formal request.

Conflicts of Interest: The authors declare no conflict of interest. The funders had no role in the design of the study; in the collection, analyses, or interpretation of data; in the writing of the manuscript, or in the decision to publish the results.

\section{References}

1. Percy-Cunningham, J.E.; MacDonald, J.A. Biology and ultrastructure of sex pheromone-producing glands. In Pheromone Biochemistry; Prestwich, G.D., Blomquist, G.J., Eds.; Academic Press: Orlando, FL, USA, 1987; pp. $27-69$.

2. Cardé, R.T.; Cardé, A.M.; Hill, A.S.; Roelofs, W.L. Sex pheromone specificity as a reproductive isolating mechanism among the sibling species, Archips argyrospilus and A. mortuanus and other sympatric tortricine moths (Lepidoptera: Tortricidae). J. Chem. Ecol. 1977, 3, 71-84. [CrossRef]

3. Millar, J. The devil is in the details. J. Chem. Ecol. 2014, 40, 517-518. [CrossRef]

4. Jurenka, R. Insect pheromone biosynthesis. Top. Curr. Chem. 2004, 239, 97-132. [CrossRef] [PubMed]

5. Roelofs, W.L.; Jurenka, R.A. Biosynthetic enzymes regulating ratios of sex pheromone components in female redbanded leafroller moths. Bioorg. Med. Chem. 1996, 4, 461-466. [CrossRef]

6. Tillman, J.A.; Seybold, S.J.; Jurenka, R.A.; Blomquist, G.J. Insect pheromones-an overview of biosynthesis and endocrine regulation. Insect Biochem. Mol. Biol. 1999, 29, 481-514. [CrossRef]

7. Jurenka, R. Regulation of pheromone biosynthesis in moths. Curr. Opin. Insect Sci. 2017, 24, 29-35. [CrossRef]

8. Zhu, J.W.; Millar, J.; Löfstedt, C. Hormonal regulation of sex pheromone biosynthesis in the turnip moth, Agrotis segetum. Arch. Insect Biochem. Physiol. 1995, 30, 41-59. [CrossRef]

9. Volpe, J.J.; Vagelos, P.R. Saturated fatty acid biosynthesis and its regulation. Annu. Rev. Biochem. 1973, 42, 21-60. [CrossRef] 
10. Wang, H.-L.; Liénard, M.A.; Zhao, C.-H.; Wang, C.-Z.; Löfstedt, C. Neofunctionalization in an ancestral insect desaturase lineage led to rare $\Delta 6$ pheromone signals in the Chinese tussah silkworm. Insect Biochem. Mol. Biol. 2010, 40, 742-751. [CrossRef]

11. Liénard, M.A.; Lassance, J.-M.; Wang, H.-L.; Zhao, C.-H.; Piškur, J.; Johansson, T.; Löfstedt, C. Elucidation of the sex-pheromone biosynthesis producing 5,7-dodecadienes in Dendrolimus punctatus (Lepidoptera: Lasiocampidae) reveals $\Delta 11$ - and $\Delta$ 9-desaturases with unusual catalytic properties. Insect Biochem. Mol. Biol. 2010, 40, 440-452. [CrossRef]

12. Hagström, A.K.; Albre, J.; Tooman, L.K.; Thirmawithana, A.H.; Corcoran, J.; Löfstedt, C.; Newcomb, R.D. A novel fatty acyl desaturase from the pheromone glands of Ctenopseustis obliquana and C. herana with specific Z5-desaturase activity on myristic acid. J. Chem. Ecol. 2014, 40, 63-70. [CrossRef]

13. Xia, Y.-H.; Zhan, Y.-N.; Ding, B.-J.; Wang, H.-L.; Löfstedt, C. Multi-functional desaturases in two Spodoptera moths with $\Delta 11$ and $\Delta 12$ desaturation activities. J. Chem. Ecol. 2019, 45, 378-387. [CrossRef]

14. Butenandt, A.; Beckman, R.; Stamm, D.; Hecker, E. Über den sexual-lockstoff des seidenspinner Bombyx mori, reidarstellung und constitution. Z. Naturf. B. 1959, 14, 283-284.

15. Ramaswamy, S.B.; Randle, S.A.; Ma, W.K. Field evaluation of the sex pheromone components of Heliothis virescens (Lepidoptera, Noctuidae) in cone traps. Environ. Entomol. 1985, 14, 293-296. [CrossRef]

16. Chisholm, M.D.; Steck, W.F.; Underhill, E.W.; Palaniswamy, P. Field trapping of diamondback moth Plutella xylostella using an improved four-component sex attractant blend. J. Chem. Ecol. 1983, 9, 113-1188. [CrossRef] [PubMed]

17. Sofer, W.; Martin, P.F. Analysis of alcohol dehydrogenase gene expression in Drosophila. Ann. Rev. Genet. 1987, 21, 203-225. [CrossRef] [PubMed]

18. Jurenka, R.A.; Roelofs, W.L. Characterization of the acetyltransferase used in pheromone biosynthesis in moths: Specificity for the $\mathrm{Z}$ isomer in tortricidae. Insect Biochem. 1989, 19, 639-644. [CrossRef]

19. Li, R.T.; Ning, C.; Huang, L.Q.; Dong, J.F.; Li, X.; Wang, C.Z. Expressional divergences of two desaturase genes determine the opposite ratios of two sex pheromone components in Helicoverpa armigera and Helicoverpa assulta. Insect Biochem. Mol. Biol. 2017, 90, 90-100. [CrossRef]

20. Rybczynski, R.; Vogt, R.G.; Lerner, M.R. Antennal-specific pheromone-degrading aldehyde oxidases from the moths Antheraea polyphemus and Bombyx mori. J. Biol. Chem. 1990, 265, 19712-19715. [CrossRef]

21. Teal, P.E.A.; Tumlinson, J.H. The role of alcohols in pheromone biosynthesis by two noctuid moths that use acetate pheromone components. Arch. Insect Biochem. Physiol. 1987, 4, 261-269. [CrossRef]

22. Matsumoto, S.; Hull, J.J.; Ohnishi, A.; Moto, K.; Fónagy, A. Molecular mechanisms underlying sex pheromone production in the silkmoth, Bombyx mori: Characterization of the molecular components involved in bombykol biosynthesis. J. Insect Physiol. 2007, 53, 752-759. [CrossRef]

23. Matsumoto, S.; Ohnishi, A.; Lee, J.M.; Hull, J.J. Unraveling the pheromone biosynthesis activating neuropeptide (PBAN) signal transduction cascade that regulates sex pheromone production in moths. Vitam. Horm. 2010, 83, 425-445. [CrossRef]

24. Groot, A.T.; Dekker, T.; Heckel, D.G. The genetic basis of pheromone evolution in moths. Annu. Rev. Entomol. 2016, 61, 99-117. [CrossRef]

25. Moto, K.; Suzuki, M.G.; Hull, J.J.; Kurata, R.; Takahashi, S.; Yamamoto, M.; Okano, K.; Imai, K.; Ando, T.; Matsumoto, S. Involvement of a bifunctional fatty-acyl desaturase in the biosynthesis of the silkmoth, Bombyx mori, sex pheromone. Proc. Natl. Acad. Sci. USA 2004, 101, 8631-8636. [CrossRef]

26. Ohnishi, A.; Hull, J.J.; Matsumoto, S. Targeted disruption of genes in the Bombyx mori sex pheromone biosynthetic pathway. Proc. Natl. Acad. Sci. USA 2006, 103, 4398-4403. [CrossRef] [PubMed]

27. Moto, K.; Yoshiga, T.; Yamamoto, M.; Takahashi, S.; Okano, K.; Ando, T.; Nakata, T.; Matsumoto, S. Pheromone gland-specific fatty acyl reductase of the silkmoth, Bombyx mori. Proc. Natl. Acad. Sci. USA 2003, 100, 9156-9161. [CrossRef]

28. Ohnishi, A.; Hashimoto, K.; Imai, K.; Matsumoto, S. Functional characterization of the Bombyx mori fatty acid transport protein (BmFATP) within the silkmoth pheromone gland. J. Biol. Chem. 2009, 284, 5128-5136. [CrossRef] [PubMed]

29. Matsumoto, S.; Yoshiga, T.; Yokoyama, N.; Iwanaga, M.; Koshiba, S.; Kigawa, T.; Hirota, H.; Yokoyama, S.; Okano, K.; Mita, K.; et al. Characterization of acyl-CoA-binding protein (ACBP) in the pheromone gland of the silkworm, Bombyx mori. Insect Biochem. Mol. Biol. 2001, 31, 603-609. [CrossRef]

30. Du, M.; Yin, X.; Zhang, S.; Zhu, B.; Song, Q.; An, S. Identification of lipases involved in PBAN stimulated pheromone production in Bombyx mori using the DGE and RNAi approaches. PLoS ONE 2012, 7, e31045. [CrossRef] [PubMed]

31. Roelofs, W.L.; Liu, W.; Hao, G.; Jiao, H.; Rooney, A.P.; Linn, C.E., Jr. Evolution of moth sex pheromones via ancestral genes. Proc. Natl. Acad. Sci. USA 2002, 99, 13621-13626. [CrossRef]

32. Lassance, J.-M.; Liénard, M.A.; Antony, B.; Qian, S.; Fujii, T.; Tabata, J.; Ishikawa, Y.; Löfstedt, C. Functional consequences of sequence variation in the pheromone biosynthetic gene pgFAR for Ostrinia moths. Proc. Natl. Acad. Sci. USA 2013, 110, $3967-3972$. [CrossRef] [PubMed]

33. Liénard, M.A.; Hagström, A.K.; Lassance, J.-M.; Löfstedt, C. Evolution of multicomponent pheromone signals in small ermine moths involves a single fatty-acyl reductase gene. Proc. Natl. Acad. Sci. USA 2010, 107, 10955-10960. [CrossRef] [PubMed]

34. Antony, B.; Ding, B.-J.; Moto, K.; Aldosari, S.A.; Aldawood, A.S. Two fatty acyl reductases involved in moth pheromone biosynthesis. Sci. Rep. 2016, 6, 29927. [CrossRef] 
35. Qian, S.; Fujii, T.; Ito, K.; Nakano, R.; Ishikawa, Y. Cloning and functional characterization of a fatty acid transport protein (FATP) from the pheromone gland of a lichen moth, Eilema japonica, which secretes an alkenyl sex pheromone. Insect Biochem. Mol. Biol. 2011, 41, 22-28. [CrossRef]

36. Luxova, A.; Svatos, A. Substrate specificity of membrae-bound alcohol oxidase from the tobacco hornworm moth (Manduca sexta) female pheromone glands. J. Mol. Cata. B Enzym. 2006, 38, 37-42. [CrossRef]

37. Kiyota, R.; Arakawa, M.; Yamakawa, R.; Yasmin, A.; Ando, T. Biosynthetic pathways of the sex pheromone components and substrate selectivity of the oxidation enzymes working in pheromone glands of the fall webworm, Hyphantria cunea. Insect Biochem. Mol. Biol. 2011, 41, 362-369. [CrossRef]

38. Teal, P.E.A.; Tumlinson, J.H. Terminal steps in pheromone biosynthesis by Heliothis virescens and H. zea. J. Chem. Ecol. 1986, 12, 353-366. [CrossRef]

39. Vogel, H.; Heidel, A.J.; Heckel, D.G.; Groot, A.T. Transcriptome analysis of the sex pheromone gland of the noctuid moth Heliothis virescens. BMC Genom. 2010, 14, 11-29. [CrossRef] [PubMed]

40. Zhang, Y.-N.; Xia, Y.-H.; Zhu, J.-Y.; Li, S.-Y.; Dong, S.-L. Putative pathway of sex pheromone biosynthesis and degradation by expression patterns of genes identified from female pheromone gland and adult antenna of Sesamia inferens (Walker). J. Chem. Ecol. 2014, 40, 439-451. [CrossRef]

41. Wang, Q.-H.; Gong, Q.; Fang, S.-M.; Liu, Y.-Q.; Zhang, Z.; Yu, Q.-Y. Identification of genes involved in sex pheromone biosynthesis and metabolic pathway in the Chinese oak silkworm, Antheraea pernyi. Int. J. Biol. Macromol. 2020, 163, 1487-1497. [CrossRef] [PubMed]

42. Yamamoto, K.; Higashiura, A.; Suzuki, M.; Shiotsuki, T.; Sugahara, R.; Fujii, T.; Nakagawa, A. Structural characterization of an aldo-keto reductase (AKR2E5) from the silkworm Bombyx mori. Biochem. Biophys. Res. Commun. 2016, 474, 104-110. [CrossRef]

43. Choo, Y.-M.; Pelletier, J.; Atungulu, E.; Leal, W.S. Identification and characterization of an antennae-specific aldehyde oxidase from the navel orangeworm. PLoS ONE 2013, 8, e67794. [CrossRef]

44. Wang, M.-M.; He, M.; Wang, H.; Ma, Y.-F.; Dewer, Y.; Zhang, F.; He, P. A candidate aldehyde oxidase in the antennae of the diamondback moth, Plutella xylostella (L.), is potentially involved in the degradation of pheromones, plant-derived volatiles and the detoxification of xenobiotics. Pestic. Biochem. Physiol. 2021, 171, 104726. [CrossRef] [PubMed]

45. Rybczynski, R.; Reagan, J.; Lerner, M.R. A pheromone-degrading aldehyde oxidase in the antennae of the moth Manduca sexta. J. Neurosci. 1989, 9, 1341-1353. [CrossRef] [PubMed]

46. Sun, W.; Yu, H.; Shen, Y.; Banno, Y.; Xiang, Z.; Zhang, Z. Phylogeny and evolutionary history of the silkworm. Sci. China Life Sci. 2012, 55, 483-496. [CrossRef]

47. Daimon, T.; Fujii, T.; Fujii, T.; Yokoyama, T.; Katsuma, S.; Shinoda, T.; Shimada, T.; Ishikawa, Y. Reinvestigation of the sex pheromone of the wild silkmoth Bombyx mandarina: The effects of bombykal and bombykyl acetate. J. Chem. Ecol. 2012, 38, 1031-1035. [CrossRef]

48. Kasang, G.; Kaissling, K.E.; Vostrowsky, O.; Bestmann, H.J. Bombykal, a second pheromone component of the silkworm moth Bombyx mori L. Angew. Chem. Lnt. Ed. Engl. 1978, 17, 60. [CrossRef]

49. Kim, D.; Langmead, B.; Salzberg, S.L. HISAT: A fast spliced aligner with low memory requirements. Nat. Methods. 2015, 12, 357-360. [CrossRef]

50. Pertea, M.; Pertea, G.M.; Antonescu, C.M.; Chang, T.C.; Mendell, J.T.; Salzberg, S.L. StringTie enables improved reconstruction of a transcriptome from RNA-seq reads. Nat. Biotechnol. 2015, 33, 290-295. [CrossRef]

51. Darriba, D.; Posada, D.; Kozlov, A.M.; Stamatakis, A.; Morel, B.; Flouri, T. ModelTest-NG: A new and scalable tool for the selection of DNA and protein evolutionary models. Mol. Biol. Evol. 2020, 37, 291-294. [CrossRef]

52. Kozlov, A.M.; Darriba, D.; Flouri, T.; Morel, B.; Stamatakis, A. RAxML-NG: A fast, scalable and user-friendly tool for maximum likelihood phylogenetic inference. Bioinformatics 2019, 35, 4453-4455. [CrossRef]

53. Pfaffl, M.W. A new mathematical model for relative quantification in real-time RT-PCR. Nucleic Acids Res. 2001, 29, e45. [CrossRef]

54. Ando, T.; Kasuga, K.; Yayma, Y.; Katoaka, H.; Suzuki, A. Termination of sex pheromone production in mated females of the silkworm moth. Arch. Insect Biochem. 1996, 31, 207-218. [CrossRef]

55. Ahn, S.J.; Choi, M.Y.; Boo, K.S. Mating effect on sex pheromone production of the oriental tobacco budworm, Helicoverpa assulta. J. Asia-Pacif. Entomol. 2002, 5, 43-48. [CrossRef]

56. Zhang, S.; Liu, X.; Zhu, B.; Yin, X.; Du, M.; Song, Q.; An, S. Identification of differentially expressed genes in the pheromone glands of mated and virgin Bombyx mori by digital gene expression profiling. PLoS ONE 2014, 9, e111003. [CrossRef]

57. Teal, P.E.A.; Tumlinson, J.H. Properties of cuticular oxidases used for sex pheromone biosynthesis by Heliothis zea. J. Chem. Ecol. 1988, 14, 2131-2145. [CrossRef] [PubMed]

58. He, P.; Zhang, Y.-F.; Hong, D.-Y.; Wang, J.; Wang, X.-L.; Zuo, L.-H.; Tang, X.-F.; Xu, W.-M.; He, M. A reference gene set for sex pheromone biosynthesis and degradation genes from the diamondback moth, Plutella xylostella, based on genome and transcriptome digital gene expression analyses. BMC Genom. 2017, 18, 219. [CrossRef]

59. Garattini, E.; Terao, M. Aldehyde oxidase and its importance in novel drug discovery: Present and future challenges. Expert Opin. Drug Discov. 2013, 8, 641-654. [CrossRef] [PubMed]

60. Zhang, Y.; Yang, Y.; Shen, G.; Mao, X.; Jiao, M.; Lin, Y. Identification and characterization of aldehyde oxidase 5 in the pheromone gland of the silkworm (Lepidoptera: Bombycidae). J. Insect Sci. 2020, 20, 31. [CrossRef] [PubMed] 
61. Pelletier, J.; Bozzolan, F.; Solvar, M.; François, M.-C.; Jacquin-Joly, E.; Maïbèche-Coisne, M. Identification of candidate aldehyde oxidases from the silkworm Bombyx mori potentially involved in antennal pheromone degradation. Gene 2007, 404, 31-40. [CrossRef] [PubMed]

62. Yang, Y.; Lin, Y.; Yang, C.W.; Wang, Y.X.; Xia, Q.Y. Identification and expression profiling of aldehyde oxidase genes in the silkworm, Bombyx mori. Acta Entomol. Sin. 2010, 53, 1-8. (In Chinese) 